\title{
Intracranial pressure monitoring in pediatric and adult patients with hydrocephalus and tentative shunt failure: a single-center experience over 10 years in 146 patients
}

\author{
Terje Sæhle, MD, ${ }^{1}$ and Per Kristian Eide, MD, PhD ${ }^{1,2}$ \\ 'Department of Neurosurgery, Oslo University Hospital-Rikshospitalet; and 'Faculty of Medicine, University of Oslo, Norway
}

OBJECT In patients with hydrocephalus and shunts, lasting symptoms such as headache and dizziness may be indicative of shunt failure, which may necessitate shunt revision. In cases of doubt, the authors monitor intracranial pressure (ICP) to determine the presence of over- or underdrainage of CSF to tailor management. In this study, the authors reviewed their experience of ICP monitoring in shunt failure. The aims of the study were to identify the complications and impact of ICP monitoring, as well as to determine the mean ICP and characteristics of the cardiac-induced ICP waves in pediatric versus adult over- and underdrainage.

METHODS The study population included all pediatric and adult patients with hydrocephalus and shunts undergoing diagnostic ICP monitoring for tentative shunt failure during the 10-year period from 2002 to 2011 . The patients were allocated into 3 groups depending on how they were managed following ICP monitoring: no drainage failure, overdrainage, or underdrainage. While patients with no drainage failure were managed conservatively without further actions, over- or underdrainage cases were managed with shunt revision or shunt valve adjustment. The ICP and ICP wave scores were determined from the continuous ICP waveforms.

RESULTS The study population included 71 pediatric and 75 adult patients. There were no major complications related to ICP monitoring, but 1 patient was treated for a postoperative superficial wound infection and another experienced a minor bleed at the tip of the ICP sensor. Following ICP monitoring, shunt revision was performed in $74(51 \%)$ of 146 patients, while valve adjustment was conducted in $17(12 \%)$ and conservative measures without any actions in $55(38 \%)$. Overdrainage was characterized by a higher percentage of episodes with negative mean ICP less than -5 to $-10 \mathrm{~mm}$ $\mathrm{Hg}$. The ICP wave scores, in particular the mean ICP wave amplitude (MWA), best differentiated underdrainage. Neither mean ICP nor MWA levels showed any significant association with age.

CONCLUSIONS In this cohort of pediatric and adult patients with hydrocephalus and tentative shunt failure, the risk of ICP monitoring was very low, and helped the authors avoid shunt revision in $49 \%$ of the patients. Mean ICP best differentiated overdrainage, which was characterized by a higher percentage of episodes with negative mean ICP less than -5 to $-10 \mathrm{~mm} \mathrm{Hg}$. Underdrainage was best characterized by elevated MWA values, indicative of impaired intracranial compliance.

http://thejns.org/doi/abs/10.3171/2014.12.JNS141029

KEY WORDS pediatric hydrocephalus; shunt failure; intracranial pressure; single pressure waves

$\mathrm{S}$ HUNT surgery is the primary treatment of pediatric and adult hydrocephalus, ${ }^{42}$ although shunt failure requiring shunt revision is frequent. . $^{2,8,12,45}$ Shunt failure may be accompanied by over- or underdrainage of CSF. When the shunt is draining too much CSF (overdrainage), symptoms such as headache and dizziness may arise.,937 However, symptoms such as headache and dizziness may also be caused by CSF underdrainage, e.g., due to obstruction of the CSF catheter. ${ }^{10}$ The shunt valves with adjustable
CSF opening pressure have been reported to reduce the occurrence of shunt failures. ${ }^{48}$ However, in a recent randomized controlled dual-center trial, ${ }^{39}$ we found the same rate of shunt complications and overdrainage symptoms in patients with hydrocephalus receiving a shunt with a fixed valve setting of $13 \mathrm{~cm} \mathrm{H}_{2} \mathrm{O}$, as compared with those in whom gradual lowering of the valve setting to a mean of $7 \mathrm{~cm} \mathrm{H}_{2} \mathrm{O}$ was performed. These results highlight the need for a better understanding of how shunts influence in-

ABBREVIATIONS ICP = intracranial pressure; MWA = mean ICP wave amplitude; $R T=$ mean wave rise time; $R T C=$ mean wave rise time coefficient.

SUBMITTED May 6, 2014. ACCEPTED December 18, 2014.

INCLUDE WHEN CITING Published online February 13, 2015; DOI: 10.3171/2014.12.JNS141029.

DISCLOSURE Dr. Eide has a financial interest in the software company (dPCom AS, Oslo) that manufactures the Sensometrics software used for analysis of the ICP recordings. 
tracranial pressure (ICP) dynamics during preferred CSF drainage, and in shunt failure-related overdrainage or underdrainage.

To improve the management of patients with shunted hydrocephalus with lasting symptoms indicative of shunt failure, neurosurgeons have monitored the ICP. $1,5,15,25,40,43,46$ The aim has been to pinpoint the type of shunt failure (over- or underdrainage, or no drainage failure), and to reduce the number of shunt revisions. The rationale has been that shunt surgery involves greater risks than ICP monitoring per se, given the fact that shunt surgery for hydrocephalus includes the risk of significant complications such as bleeds ${ }^{34}$ and infection, ${ }^{30,44}$ and the fact that shunt revisions increase the risk of infection..$^{41}$

In our department, diagnostic ICP monitoring has been used for years in assessment of patients with shunted hydrocephalus with lasting symptoms and possible shunt failure, unless noninvasive methods have already clarified a probable diagnosis. ${ }^{15}$ Since 2002 , we have incorporated monitoring of ICP waves to even better characterize the type of shunt failure. The ICP wave, particularly the ICP wave amplitude, is a substitute marker of the intracranial compliance (pressure-volume reserve capacity), ${ }^{20,28}$ which may play an important pathophysiological role in hydrocephalus. ${ }^{29}$ Thus, in experimental shunt failure in animals with hydrocephalus, alterations in intracranial compliance played an important role in determining the type of shunt failure. ${ }^{26}$ To further our understanding of this issue, we performed a retrospective and descriptive study to review our results of ICP monitoring in patients with shunted hydrocephalus and possible shunt failure.

\section{Methods}

\section{Patients and Study Design}

The patient population consisted of all pediatric and adult patients with shunted hydrocephalus who underwent continuous ICP wave and ICP monitoring for tentative shunt failure during the period from 2002 to 2011 within the Department of Neurosurgery at Oslo University Hospital-Rikshospitalet. The study was approved by the Oslo University Hospital-Rikshospitalet as a quality study. The Regional Committee for Medical and Health Research Ethics of Health Region South-East, Norway, was informed in writing and had no objections to the study.

The aim of the present work was to perform a retrospective descriptive study on all patients with shunts who had undergone continuous ICP wave and ICP monitoring for tentative shunt failure to establish information on: 1) the complication profile of ICP monitoring; 2) the frequency of when shunt revision was avoided; and 3) a profile of alterations in ICP waves and ICP depending on the type of shunt failure. The hypothesis was that ICP scores changed differently depending on the type of shunt failure.

\section{Algorithm for Management of Shunt Failure}

Our department's algorithm for management of shunt failure is illustrated in Fig. 1. In brief, the diagnosis of shunt failure is based on the patient's history, as well as clinical and imaging findings. The likelihood for shunt failure depends on the available information. Evidence in favor of shunt failure may be clear when imaging shows disconnection of the shunt system, misplacement of catheters, and growing ventricles. On the other hand, in patients with no obvious imaging findings, unclear clinical presentation, and absence of other probable causes of the patient's symptoms, diagnostic ICP monitoring is used to aid management. Thus, the indication for diagnostic ICP monitoring in shunt failure is based on the following: 1) imaging of cerebral ventricles and the shunt system that provides no clear diagnosis of shunt failure or type of tentative shunt failure; 2 ) the patient presents with symptoms that may indicate shunt failure, even though the history and symptoms are not clear for shunt failure; 3) the symptoms last for weeks or months, and are not responding to conservative measures such as medication or shunt-valve adjustment; and 4) noninvasive assessment has not revealed other probable causes of the symptoms. Diagnostic ICP monitoring is then used to select management strategy (Fig. 1). Because the type of shunt failure could not be determined from the imaging findings in these patients, it was beyond the scope of this study to explore how shunt failure relates to findings on CT scans and MR images.

\section{Shunt Failure Management Groups}

We allocated the patients into 3 groups based on the conclusion about the type of shunt failure as diagnosed by the attending neurosurgeons and described in the discharge summary. The physician then made his or her conclusion about the type of shunt failure from the ICP scores, any effect of valve adjustments, perioperative findings, and immediate postoperative clinical improvement of the patient. When the diagnosis of type of shunt failure was made, there was no awareness of a study on the topic.

The first group was no drainage failure. Patients in this group were considered to have normal CSF drainage, and conservative follow-up without any action was advocated. Review of the patient records confirmed that none of the patients in this group underwent shunt revision within the following 30 days. The second group was the overdrainage group. Patients within the overdrainage group underwent measures to reduce CSF overdrainage, including upward adjustment of the valve setting or implantation of an antisiphon device. The final group was those patients with underdrainage. Patients within the underdrainage group underwent shunt revision or lowering of the opening pressure of the shunt valve to prevent underdrainage.

\section{Analysis of Continuous ICP Wave and ICP Recordings}

Our institutional routine for diagnostic ICP monitoring for tentative shunt failure is as follows. A small bur hole is made in the skull, and a minor opening is made in the dura. A Codman ICP Microsensor (Johnson and Johnson) is tunneled subcutaneously, zeroed against the atmospheric pressure, and introduced $1-2 \mathrm{~cm}$ into the frontal brain parenchyma. The Codman ICP Microsensor is connected to the Codman ICP Express monitoring system (Johnson and Johnson), and then connected to an analog-digital converter (Sensometrics Pressure Logger, dPCom), which is connected to a computer with the Sensometrics Software (dPCom) used for online recording of ICP signals 

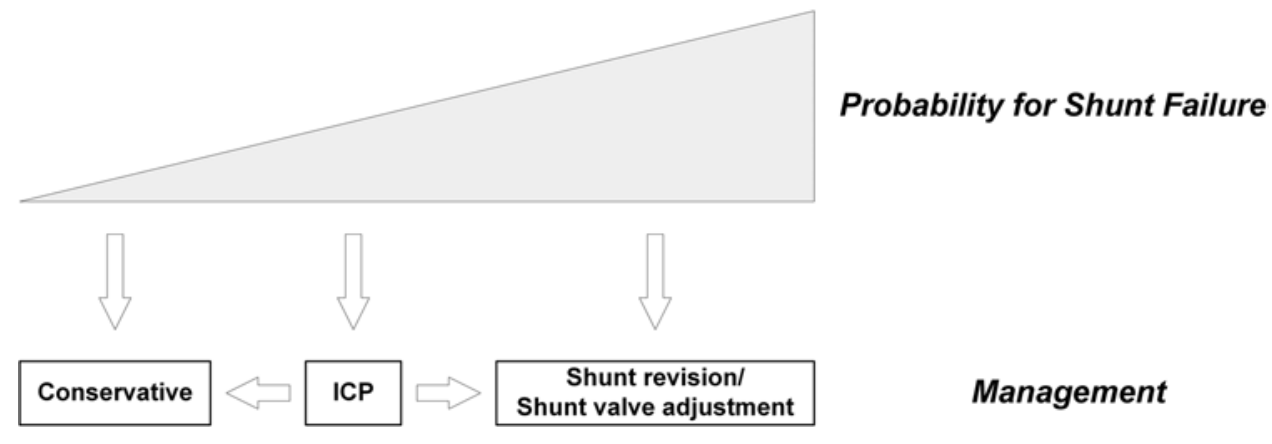

Management

FIG. 1. The algorithm for management of patients with hydrocephalus and tentative shunt failure. The diagnosis of shunt failure is based on the patient's history, clinical findings, and imaging results. Depending on the clinical/radiological information, the probability of shunt failure is weak (left) or strong (right). The management of shunt failure ranges from conservative measures (observation, medication, etc.) to shunt revision depending on the probability for shunt failure. Diagnostic ICP monitoring is used to select management strategy.

(sampling rate $200 \mathrm{~Hz}$ ). The continuous ICP monitoring is conducted within the neurosurgical ward from one day to another. The continuous ICP raw signals were stored on the hospital server for retrospective analysis.

The continuous ICP waveforms of the included patients were analyzed using a previously published method for automatic cardiac-induced ICP waves, ${ }^{14}$ and implemented in the Sensometrics software. The automatic ICP waveform analysis incorporates several automatic steps: 1) identifying the cardiac-induced waves by their beginning and ending diastolic minimum pressures and systolic maximum pressure; 2 ) determining the amplitude (pulse amplitude, dP), rise time (dT), and rise time coefficient (RTC, dP/dT) from the identified cardiac-beat-induced ICP waves; and 3) for each 6-second time window, computing the ICP waveform indices mean ICP wave amplitude (MWA), mean wave rise time (RT) and mean wave rise time coefficient (RTC); the static pressure (mean ICP) is also computed for each 6-second time window. Only 6 -second time windows containing a minimum of 4 cardiac beat-induced waves are considered to be of good quality and were used for the present analysis. The automatic method also identifies artifact waves due to noise in the pressure signal, due to patient movement or sensor move- ment or dysfunction, and thus artifact waves were omitted from the analysis.

A standardized recording time from 11 PM until 7 AM was applied to compare the pressure scores between patients. The ICP scores were compared with another recording time from 7 AM until 10 AM.

\section{Statistical Analysis}

Statistical analysis was performed using the program SPSS (version 20, IBM Corp.). Differences between groups were determined using 1-way ANOVA with Bonferroni corrected post hoc tests. Associations between observations were determined by the Pearson correlation coefficient. Differences between tabular categories were determined using the Pearson chi-square test. Significance was accepted at the 0.05 level of probability.

\section{Results}

\section{Demographic and Clinical Data}

During the period from 2002 to 2011,71 pediatric and 75 adult patients with shunted hydrocephalus underwent diagnostic ICP monitoring for tentative shunt failure. Demographic data are shown in Table 1. Following ICP moni-

TABLE 1. Demographic and clinical data of the management groups

\begin{tabular}{|c|c|c|c|c|c|c|}
\hline \multirow[b]{2}{*}{ Variable } & \multicolumn{3}{|c|}{ Pediatric Hydrocephalus $(n=71)$} & \multicolumn{3}{|c|}{ Adult Hydrocephalus ( $n=75)$} \\
\hline & No Drainage Failure & Overdrainage & Underdrainage & No Drainage Failure & Overdrainage & Underdrainage \\
\hline No. of patients (\%) & $25(35)$ & $9(13)$ & $37(52)$ & $30(40)$ & $22(29)$ & $23(31)$ \\
\hline $\operatorname{Sex}(F / M)$ & $12 / 13$ & $4 / 5$ & $13 / 24$ & $17 / 13$ & $16 / 6$ & $13 / 10$ \\
\hline Mean age in yrs (range) & $12(3-18)$ & $10(8-12)$ & $12(3-18)$ & $42(19-79)$ & $42(20-78)$ & $25(19-64)^{*}$ \\
\hline \multicolumn{7}{|l|}{ Hydrocephalus type (\%) } \\
\hline Communicating & $21(84)$ & $9(100)$ & $31(84)$ & $25(83)$ & $14(64)$ & $18(78)$ \\
\hline Noncommunicating & $4(16)$ & - & $6(16)$ & $5(17)$ & $8(36)$ & $5(22)$ \\
\hline \multicolumn{7}{|l|}{ Management (\%) } \\
\hline Shunt revision & - & $6(67)$ & $37(100)$ & - & $12(55)$ & $19(83)$ \\
\hline Shunt valve adjustment & - & $3(33)$ & - & - & $10(45)$ & $4(17)$ \\
\hline No actions & $25(100)$ & - & - & $30(100)$ & - & - \\
\hline
\end{tabular}

* Significant age difference $(p=0.004)$ between underdrainage and overdrainage/no drainage failure groups in the adult cohort (1-way ANOVA with Bonferroni corrected post hoc test). 
toring, complications were noted in $2(1.4 \%)$ of the 146 patients, including 1 superficial wound infection $(0.7 \%)$ and 1 minor bleed $(16 \times 9 \mathrm{~mm})$ at the tip of the sensor $(0.7 \%)$.

Shunt revision was performed in $74(51 \%)$ of the 146 patients subsequent to ICP monitoring. Short-term complications with shunt revision were noted in $6(8.1 \%)$ of 74 patients, including 4 shunt infections $(5.4 \%)$ and 2 cerebral bleeds from the ventricular catheter $(2.7 \%)$. The median follow-up durations were 18 and 26 months in the pediatric and adult cohorts, respectively. During the period of 2002-2011, approximately 1174 shunt revisions were completed in our department. The present cohort of 146 patients constituted $12 \%$ of this cohort.

\section{Shunt Failure Management Groups}

Figure 2 presents the proportion of patients within the 3 management groups (no drainage failure, overdrainage, and underdrainage). While underdrainage was the predominant group in the children (Fig. 2 upper), the distribution of over- and underdrainage was similar in the adults (Fig. 2 lower). No drainage failure, i.e., cases not necessitating further actions, were diagnosed in $25(35 \%)$ of 71 children (Fig. 2 upper) and $30(40 \%)$ of 75 adults (Fig. 2 lower). Moreover, shunt valve adjustment was performed in 17 patients, including $4 \%$ of the children (3/71) and $19 \%$ of the adults (14/75; Table 1). Thus, in this cohort of 146 patients, shunt revision was avoided in 72 patients (49\%).

\section{Symptoms}

In both patient cohorts, symptoms had lasted for weeks or months prior to diagnostic ICP monitoring. In the pediatric cohort, the frequency and distribution of symptoms compared between all management groups was led by headache, followed by lethargy, irritability, anorexia/nausea, and dizziness (Table 2). Likewise, headache was the most frequent complaint in all management groups in the adult cohort, followed by lethargy, anorexia/nausea, and dizziness (Table 2). We found no significant differences regarding distribution of symptoms between management groups. Neither did we find a systematic effect regarding body position and symptoms (data not shown). These observations confirm that type of shunt failure could not be determined based solely on clinical symptoms at the time of ICP monitoring.

\section{ICP Scores of the Management Groups}

Mean ICP Scores

The mean ICP scores are presented in Table 3 and Fig. 3. Mean ICP was significantly increased in the underdrainage group in both adults and children. However, the management groups were not very well differentiated by mean ICP (Table 3, Fig. 3). Accordingly, mean ICP $\geq 15$ $\mathrm{mm} \mathrm{Hg}$ in $\geq 20 \%$ of the recording time was observed in 0 of 55 of patients in the no drainage failure group, 0 of 31 patients in the overdrainage group, and 3 (5\%) of 60 in the underdrainage group (Fig. $3 \mathrm{C}$ and D). A higher percentage of negative mean ICP values $(<-5$ to $-10 \mathrm{~mm} \mathrm{Hg})$ measured in the supine position overnight characterized the overdrainage group. This observation was significant in the pediatric but not the adult cohort (Table 3).
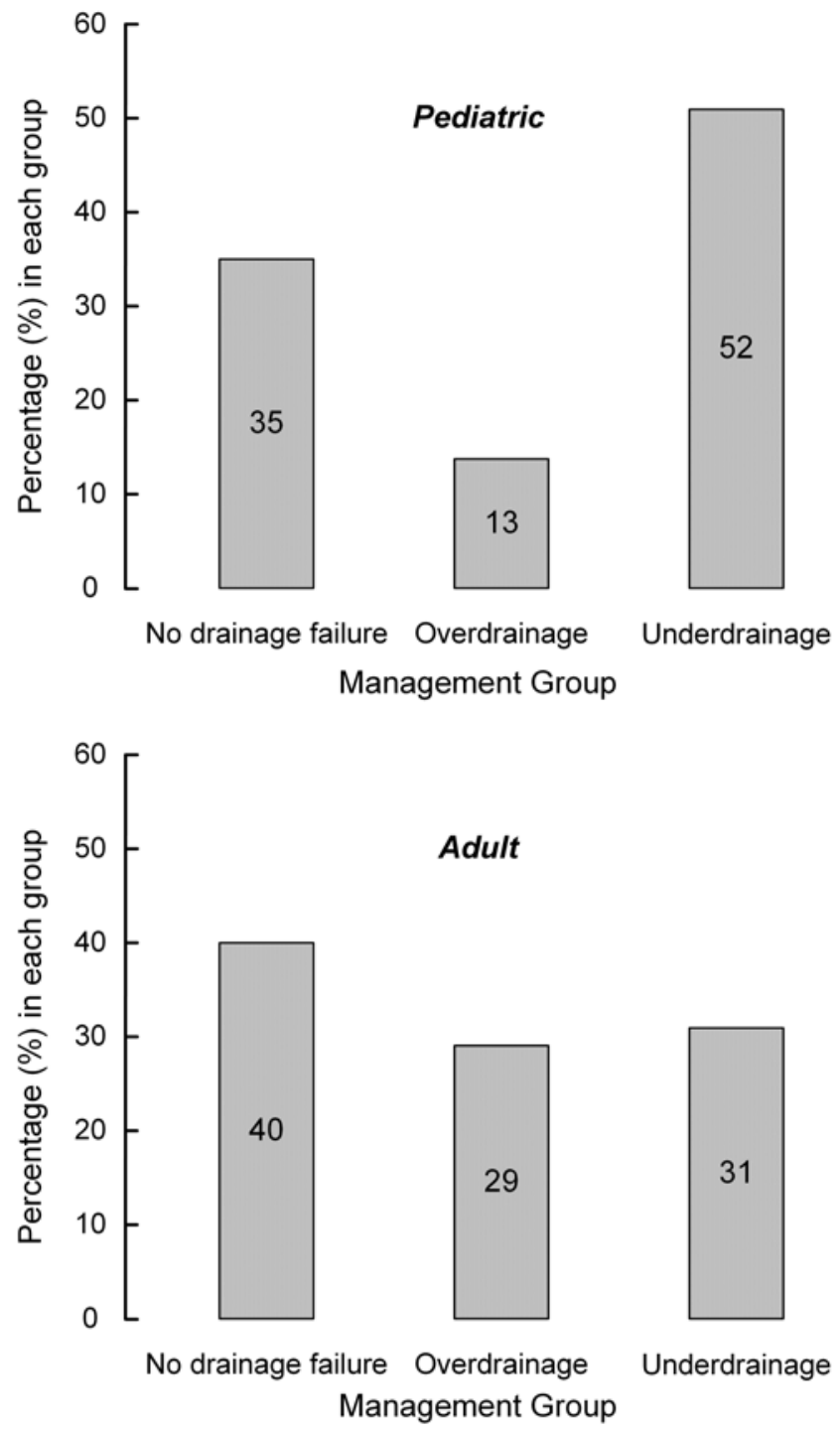

FIG. 2. Percentage of patients within the management groups denoted as no drainage failure, overdrainage, and underdrainage in the pediatric (upper) and adult (lower) patient cohorts. The proportion within each group differed between the two cohorts $(p=0.01$, Pearson chi-square test).

\section{ICP Wave Scores}

The ICP wave parameters are presented in Table 4 . The most important observations were significantly increased MWA and RTC values in the underdrainage group, both in the pediatric and adult cohorts. The differentiation of the management groups was more evident on the basis of MWA values (Fig. 4) than mean ICP (Fig. 3). Thus, when considering the total cohort, MWA $\geq 5 \mathrm{~mm} \mathrm{Hg}$ in $\geq 20 \%$ of recording time was noted in $6(11 \%)$ of 55 patients in the no drainage failure group, 3 (10\%) of 31 in the overdrainage group, and $51(85 \%)$ of 60 in the underdrainage group (Fig. 4C and D).

\section{Time of Monitoring}

The ICP scores referred to in Tables 3 and 4 and Figs. 3 and 4 refer to the recording period from 11 PM to $7 \mathrm{AM}$. 
TABLE 2. Symptoms indicative of shunt failure in the management groups*

\begin{tabular}{|c|c|c|c|c|c|c|}
\hline \multirow[b]{2}{*}{ Symptom } & \multicolumn{3}{|c|}{ Pediatric Hydrocephalus $(n=71)$} & \multicolumn{3}{|c|}{ Adult Hydrocephalus $(n=75)$} \\
\hline & $\begin{array}{l}\text { No Drainage Failure } \\
\qquad(\mathrm{n}=25)\end{array}$ & $\begin{array}{l}\text { Overdrainage } \\
\qquad(n=9)\end{array}$ & $\begin{array}{l}\text { Underdrainage } \\
\qquad(n=37)\end{array}$ & $\begin{array}{l}\text { No Drainage Failure } \\
\qquad(n=30)\end{array}$ & $\begin{array}{l}\text { Overdrainage } \\
\quad(n=22)\end{array}$ & $\begin{array}{l}\text { Underdrainage } \\
\qquad(n=23)\end{array}$ \\
\hline Headache & $18(72)$ & $9(100)$ & $28(76)$ & $20(67)$ & $17(77)$ & $21(91)$ \\
\hline Dizziness & $3(12)$ & $2(22)$ & $3(8)$ & $7(23)$ & $5(23)$ & $7(30)$ \\
\hline Irritability & $6(24)$ & $2(22)$ & $6(16)$ & $2(7)$ & $1(5)$ & - \\
\hline Anorexia/nausea & $5(20)$ & $1(11)$ & $6(16)$ & $9(30)$ & $2(9)$ & $9(39)$ \\
\hline Lethargy & $7(28)$ & $2(22)$ & $15(41)$ & $10(33)$ & $6(27)$ & $9(39)$ \\
\hline Unsteady gait & - & - & $1(3)$ & $6(20)$ & $7(32)$ & $1(4)$ \\
\hline Urinary incontinence & - & - & $1(3)$ & $2(7)$ & $3(14)$ & - \\
\hline Cognitive impairment & $1(4)$ & - & $3(8)$ & $11(37)$ & $3(14)$ & $4(17)$ \\
\hline
\end{tabular}

* Data given as number of patients (\%).

We compared ICP scores during this period with results during the recording period from $7 \mathrm{Am}$ to $10 \mathrm{Am}$. During the latter period, the patients were sitting in bed or even standing up, while during the night period (11 PM to $7 \mathrm{AM}$ ) the patients were remaining supine in bed. While mean ICP values were significantly lower during the recording period from $7 \mathrm{Am}$ to $10 \mathrm{Am}$ in all management groups, no significant differences in ICP wave parameters during the two time periods were observed (data not shown).

\section{ICP Scores and Age}

When determining how the ICP scores related to age for each management group separately, we found no significant association between mean ICP and age (Fig. 5AC) or between MWA and age (Fig. 5D-F). On the other hand, the ICP wave parameter RT was highly age-dependent (Fig. 5G-I), with increased values in older patients. Consequently, the RTC became lower with increasing age (Fig. 5J-L).

\section{Discussion}

In the present cohort of patients with shunted hydrocephalus undergoing ICP monitoring for tentative shunt failure, shunt revision was avoided in $49 \%$ of the patients. Mean ICP best differentiated overdrainage, which was characterized by increased frequency of mean ICP less than -5 to $-10 \mathrm{~mm} \mathrm{Hg}$, whereas the ICP wave amplitude best differentiated underdrainage.

\section{Shunt Failure Management Groups}

The clinical picture and severity of shunt failure in pediatric and adult hydrocephalus ranges from the acute situation with life-threatening symptoms requiring immediate surgery, to a chronic situation with symptoms lasting from weeks to months, and a questionable presence of shunt failure. The present study investigated this latter type of shunt failure with possible over- or underdrainage.

Patients were allocated into management groups (no drainage failure, overdrainage, or underdrainage) based on the conclusion made about the type of shunt failure when there was no awareness about a study on the topic. The basis for the diagnosis was a combination of the measured ICP scores, any effect of valve adjustment, perioperative findings, and any presence of immediate postoperative clinical improvement of the patient. In the no drainage failure group, no 30-day shunt surgery was recorded.

The distribution of symptoms was comparable between the different shunt failure management groups. Thus, symptoms such as headache, lethargy, dizziness, anorexia, and nausea were not more or less common depending on

TABLE 3. Mean ICP scores of the management groups*

\begin{tabular}{|c|c|c|c|c|c|c|}
\hline \multirow[b]{2}{*}{$\begin{array}{c}\text { Mean ICP } \\
(\mathrm{mm} \mathrm{Hg})\end{array}$} & \multicolumn{3}{|c|}{ Pediatric Hydrocephalus $(n=71)$} & \multicolumn{3}{|c|}{ Adult Hydrocephalus $(n=75)$} \\
\hline & $\begin{array}{l}\text { No Drainage Failure } \\
\qquad(\mathrm{n}=25)\end{array}$ & $\begin{array}{l}\text { Overdrainage } \\
\qquad(n=9)\end{array}$ & $\begin{array}{l}\text { Underdrainage } \\
\qquad(n=37)\end{array}$ & $\begin{array}{l}\text { No Drainage Failure } \\
\qquad(n=30)\end{array}$ & $\begin{array}{l}\text { Overdrainage } \\
\qquad(n=22)\end{array}$ & $\begin{array}{l}\text { Underdrainage } \\
\qquad(n=23)\end{array}$ \\
\hline Average & $9.1(-1.6$ to 16.9$)$ & $3.5(-8.8$ to 12.5$)$ & $14.4(4.8-42.6) \dagger$ & $5.4(-3.6$ to 18.6$)$ & $1.7(-9.5$ to 9.7$)$ & $10.4(3.8-66.8) \ddagger$ \\
\hline$\% \leq-10$ & $0(0-1)$ & $0(0-5) \S$ & - & $0(0-5)$ & $0(0-6)$ & 0 \\
\hline$\% \leq-5$ & $0(0-8)$ & $0(0-17) \ddagger$ & - & $0(0-6)$ & $0(0-20)$ & 0 \\
\hline$\% \geq 15$ & $0(0-11)$ & $0(0-3)$ & $5(0-20) \dagger$ & $0(0-17)$ & $0(0-1)$ & $1(0-20) \ddagger$ \\
\hline$\% \geq 20$ & $0(0-2)$ & $0(0-1)$ & $2(0-18) \ddagger$ & $0(0-3)$ & 0 & $0(0-20) \S$ \\
\hline \multicolumn{7}{|c|}{$\begin{array}{l}{ }^{*} \text { ICP parameters recorded from } 11 \text { PM to } 7 \text { AM. Data given as value (range). Within each patient cohort, significant differences between the normal-drainage group } \\
\text { compared with the over- or underdrainage groups were determined (1-way ANOVA with Bonferroni-corrected post hoc test). } \\
\dagger p<0.001 \text {. } \\
\ddagger p<0.01 \text {. } \\
\S p<0.05 \text {. }\end{array}$} \\
\hline
\end{tabular}


A
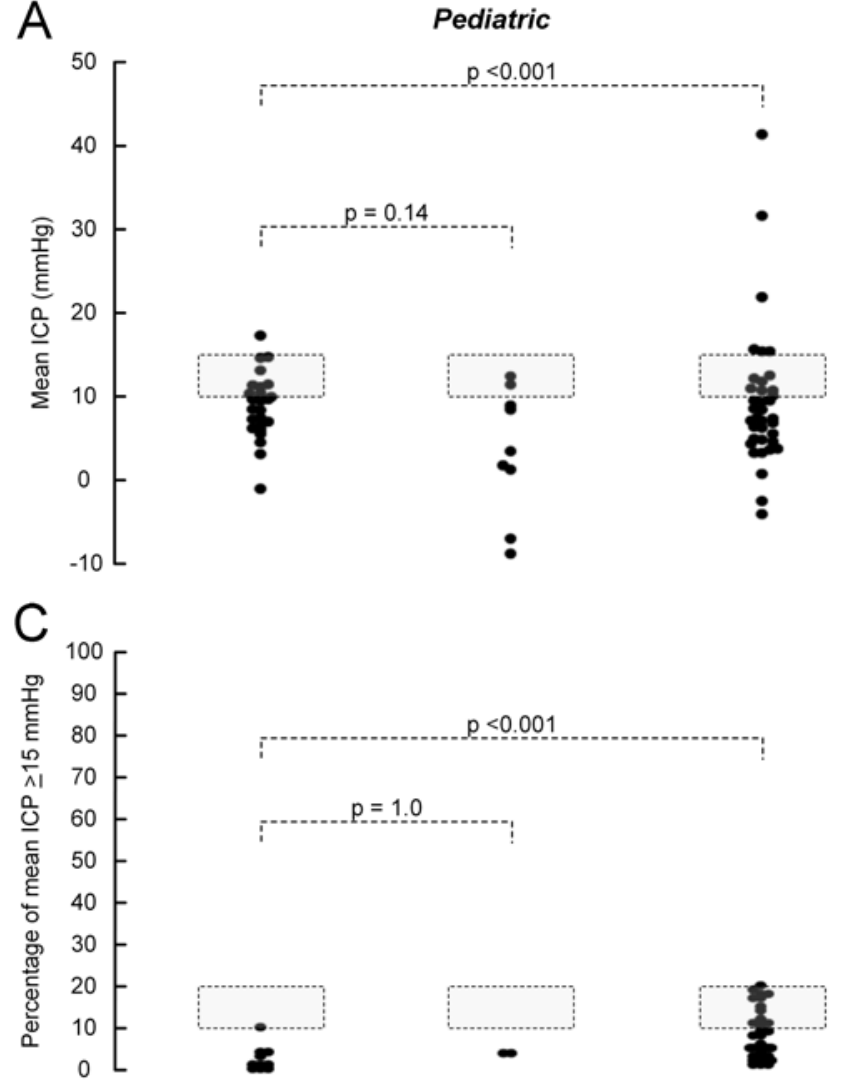

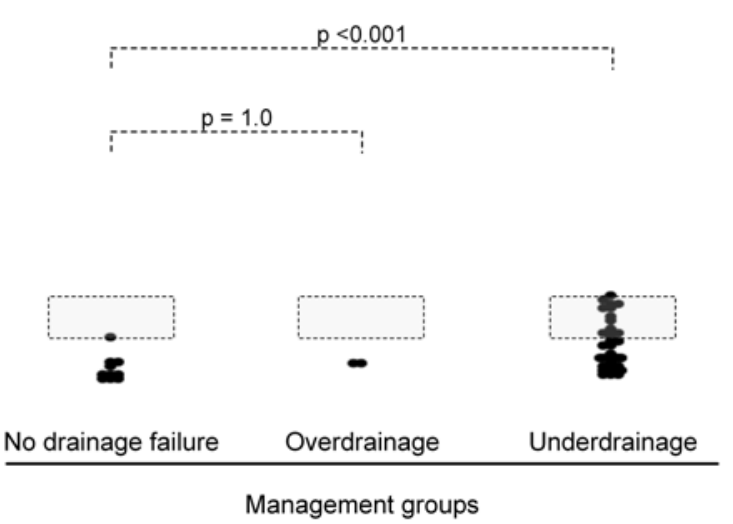

B

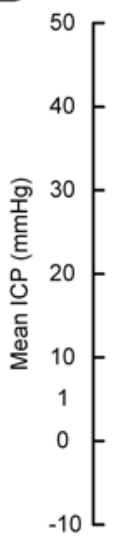

D

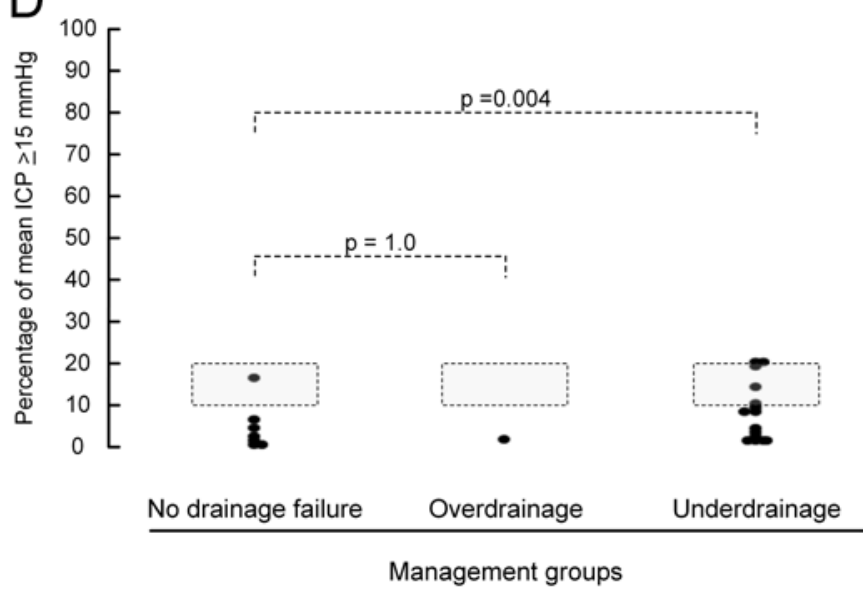

FIG. 3. Average values of mean ICP for the no drainage failure, overdrainage, and underdrainage management groups are shown in pediatric (A) and adult (B) patient cohorts, and the percentage of recording time with mean ICP $\geq 15 \mathrm{~mm} \mathrm{Hg}$ in pediatric (C) and adult (D) cohorts. Each dot represents the average value for 1 patient monitored from 11 PM to 7 AM. Boxes with dashed lines refer to a range of upper normal thresholds. Significant differences were determined by ANOVA with Bonferroni-corrected post hoc testing.

the type of shunt failure. We found no systematic pattern regarding aggravation when the patient was standing (in the overdrainage group) or worsening in the supine position (in the underdrainage group). These observations confirm that in this particular group of patients with tentative shunt failure, symptoms and position dependence could not differentiate type of shunt failure. Even in patients with shunted hydrocephalus, headache may be caused by another condition other than shunt failure. ${ }^{38}$

In the patients presented here, shunt revision or conservative management was the alternative to ICP monitoring. The rational for the approach described in this work is that invasive ICP monitoring can result in avoidance of shunt revision and also carries a lower risk for severe complications, ${ }^{6,22,27,31}$ than do shunt surgery and shunt revision. ${ }^{30,34,41}$

It was beyond the scope of this work to determine the rate of shunt failure depending on type of shunt. Neither did we explore how shunt valve adjustment could be used to modify over- or underdrainage. There is limited scientific evidence to argue that one shunt type is superior to another. ${ }^{3,12,13}$ Finally, it was beyond the scope of this study to explore how radiological measures identify causes of shunt failure. In the present cases, assessment of ventricular size and change in size over time had been investigated and considered inconclusive regarding the presence or absence of shunt failure. Other authors have previously reported that MRI findings aid in determining optimal shunt-valve opening pressure. ${ }^{35}$

\section{ICP Scores and Type of Shunt Failure}

Among the present patients with underdrainage, only modest elevations in mean ICP were noted. Hence, we found mean ICP $\geq 15 \mathrm{~mm} \mathrm{Hg}$ in $\geq 20 \%$ of the recording time (i.e., mean ICP $\geq 15 \mathrm{~mm} \mathrm{Hg}$ during 12 minutes of a 1-hour recording) in only 1 (3\%) of 37 pediatric patients (Fig. 3C) and 2 (9\%) of 23 adult patients (Fig. 3D). While shunt failure may cause impaired perfusion pressure, it is difficult to imagine how the present mean ICP values might impair cerebral perfusion pressure. On the other hand, in other situations with shunt failure accompanied by higher mean ICP, the cerebral perfusion pressure might be impaired.

While mean ICP was only marginally increased and less 
TABLE 4. Mean ICP wave scores of the management groups*

\begin{tabular}{|c|c|c|c|c|c|c|}
\hline \multirow[b]{2}{*}{ ICP Variable } & \multicolumn{3}{|c|}{ Pediatric Hydrocephalus $(n=71)$} & \multicolumn{3}{|c|}{ Adult Hydrocephalus $(n=75)$} \\
\hline & $\begin{array}{l}\text { No Drainage Failure } \\
\qquad(n=25)\end{array}$ & $\begin{array}{l}\text { Overdrainage } \\
\qquad(n=9)\end{array}$ & $\begin{array}{l}\text { Underdrainage } \\
\qquad(\mathrm{n}=37)\end{array}$ & $\begin{array}{l}\text { No Drainage Failure } \\
\qquad(n=30)\end{array}$ & $\begin{array}{l}\text { Overdrainage } \\
\qquad(\mathrm{n}=22)\end{array}$ & $\begin{array}{l}\text { Underdrainage } \\
\qquad(\mathrm{n}=23)\end{array}$ \\
\hline \multicolumn{7}{|l|}{ MWA (mm Hg) } \\
\hline Average & $3.2(1.4-5.5)$ & $3.3(2.0-4.6)$ & $5.0(3.9-10.5) \dagger$ & $2.8(1.6-4.5)$ & $2.9(1.4-4.6)$ & $5.7(4.3-9.2) \dagger$ \\
\hline$\% \geq 5$ & $1(0-68)$ & $1(0-29)$ & $38(11-99) \dagger$ & $1(0-33)$ & $1(0-28)$ & $61(19-98) \dagger$ \\
\hline$\% \geq 6$ & $0(0-25)$ & $0(0-12)$ & $20(1-92) \dagger$ & $0(0-9)$ & $0(0-15)$ & $35(5-91) \dagger$ \\
\hline \multicolumn{7}{|l|}{ Mean RT (sec) } \\
\hline Average & $0.13(0.10-0.26)$ & $0.12(0.10-0.20)$ & $0.15(0.10-0.26)$ & $0.20(0.09-0.27)$ & $0.20(0.11-0.30)$ & $0.20(0.11-0.30)$ \\
\hline$\% \geq 0.20$ & $5(0-99)$ & $1(0-49)$ & $8(0-95)$ & $50(0-100)$ & $50(0-97)$ & $51(0-99)$ \\
\hline$\% \geq 0.25$ & $1(0-70)$ & $0(0-34)$ & $2(0-76)$ & $18(0-89)$ & $15(0-86)$ & $9(0-88)$ \\
\hline \multicolumn{7}{|l|}{ Mean RTC (mm Hg/sec) } \\
\hline Average & $27.0(8.5-47.2)$ & $27.9(17.1-44.3)$ & $37.7(20.4-78.4) \dagger$ & $16.4(5.1-46.2)$ & $20.0(5.8-35.6)$ & $32.8(19.5-78.3) \dagger$ \\
\hline$\% \geq 30$ & $30(0-98)$ & $30(0-97)$ & $81(12-100) \dagger$ & $1(0-99)$ & $5(0-89)$ & $62(5-100) \ddagger$ \\
\hline$\% \geq 40$ & $2(0-80)$ & $1(0-61)$ & $42(3-100) \dagger$ & $0(0-71)$ & $0(0-18)$ & $16(1-98) \ddagger$ \\
\hline \multicolumn{7}{|l|}{ Quality of recording } \\
\hline $\begin{array}{c}\% \text { of accepted } 6-\mathrm{sec} \\
\text { time windows }\end{array}$ & $98(1-100)$ & $99(89-100)$ & $94(32-100)$ & $95(11-100)$ & $96(33-100)$ & $96(9-100)$ \\
\hline
\end{tabular}

* ICP parameters recorded from 11 PM to 7 AM. Data given as value (range). Within each patient cohort, significant differences between the normal-drainage group compared with the over- or underdrainage groups were determined (1-way ANOVA with Bonferroni-corrected post hoc test).

$+p<0.001$

$\ddagger p<0.01$.

definitive in the majority of patients in the underdrainage group, the most evident observation in patients within the overdrainage group was more negative mean ICP than that observed in the other management groups. The percentage of time with mean ICP less than -5 to $-10 \mathrm{~mm} \mathrm{Hg}$ was higher in these patients, which was significant in the pediatric cohort. Negative mean ICP in overdrainage has been shown before. ${ }^{15,24,37}$ We have previously shown that with very negative mean ICP less than $-5 \mathrm{~mm} \mathrm{Hg}$, MWA may increase, ${ }^{23}$ indicative of impaired compliance. It is thus interesting to note that in the overdrainage group, $1(11 \%)$ of 9 pediatric patients presented with MWA $\geq 5 \mathrm{~mm} \mathrm{Hg}$ in $\geq$ $20 \%$ of the recording time (Fig. 4C). In this patient, the elevated MWA was accompanied by mean ICP $\leq-10 \mathrm{~mm} \mathrm{Hg}$ in $5 \%$ of the recording time and mean ICP $\leq-5 \mathrm{~mm} \mathrm{Hg}$ in $17 \%$ of the recording time, despite the fact that the patient was supine (average mean ICP $=-8.8 \mathrm{~mm} \mathrm{Hg}$ ). Therefore, in cases with very low mean ICP, the MWA may increase.

One methodological weakness with the parameter of mean ICP is that it is sensitive to baseline pressure errors. ${ }^{18,19}$ Mean ICP refers to the static pressure relative to a baseline pressure level. Baseline pressure errors may cause an erroneous mean ICP value. The ICP wave parameters are not affected by baseline pressure errors. Moreover, the mean ICP is dependent on the position of the patient. How ICP changes when the patient moves from sitting to lying and vice versa is different in patients with shunts. ${ }^{7,24}$ The ICP wave and ICP values referred to in this present work were monitored during the time period from 11 PM to 7 AM when the patient was supine and asleep. We also compared these values with results of monitoring from $7 \mathrm{AM}$ to $10 \mathrm{Am}$ when the patient was awake, and sitting in bed. The latter measurements showed significantly lower mean
ICP values, but no significant alterations in the ICP wave parameters.

Underdrainage was best differentiated by the MWA values. The MWA values of the underdrainage cases were comparable to values noted in nontreated shunt-dependent hydrocephalus cases. ${ }^{17,21,22}$ Accordingly, the treatment goal of normalizing ICP dynamics by shunt placement was not achieved in these patients. On the other hand, the MWA scores observed in the overdrainage or no drainage failure groups were comparable to values noted in patients with hydrocephalus who did not respond to shunt treatment. ${ }^{22}$ Identifying patients with underdrainage is most important because this implies that the treatment goals have not been achieved.

In the underdrainage group, MWA $\geq 5 \mathrm{~mm} \mathrm{Hg}$ in $>$ $10 \%$ of the recording time was observed in all 60 patients, and in $>20 \%$ of the recording time in $29(78 \%)$ of 37 pediatric patients (Fig. 4C) and 22 (96\%) of 23 adult patients (Fig. 4D). We have previously shown that increasing MWA is accompanied by impaired intracranial compliance (intracranial pressure-volume reserve capacity). ${ }^{20}$ From our clinical studies, we have defined the upper threshold of MWA as $4-5 \mathrm{~mm} \mathrm{Hg}$, and percentage of MWA $>5 \mathrm{~mm}$ $\mathrm{Hg}$ in $>10 \%$ of the recording time as indicative of impaired intracranial compliance. ${ }^{16,22}$ Therefore, we consider the elevated MWA values in the underdrainage group as an indicator of impaired intracranial compliance. A key mechanism behind the effect of shunt placement may be improvement of impaired intracranial compliance. Shunt failure may, in turn, be accompanied by impaired intracranial compliance. Observations in experimental shunt failure in animals support this assumption. ${ }^{26}$

The term intracranial compliance refers to the relation- 
A
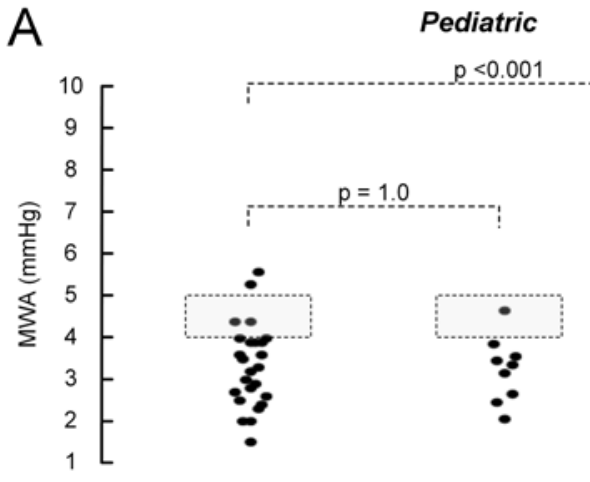

C
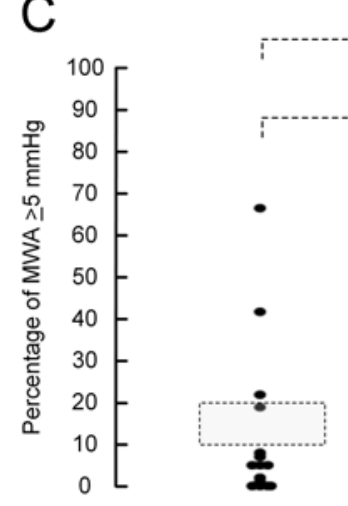

No drainage failure $p<0.001$

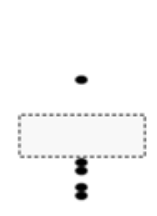

Overdrainage

Management groups
B
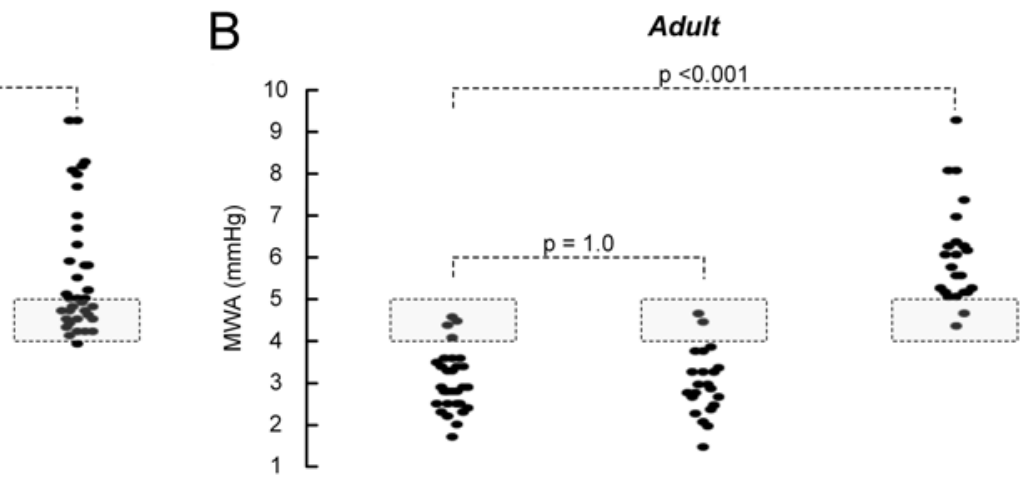

D

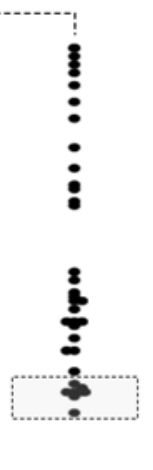

Underdrainage

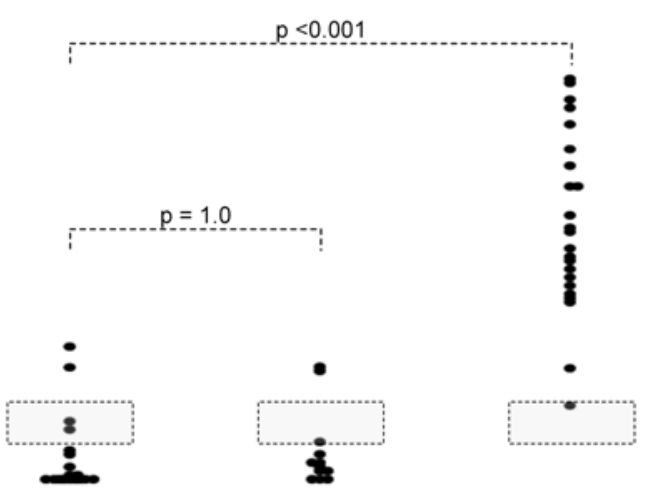

No drainage failure

Overdrainage

Underdrainage

Management groups

FIG. 4. Average values of MWA for the no drainage failure, overdrainage, and underdrainage management groups are shown in pediatric (A) and adult (B) patient cohorts, and the percentage of recording time with MWA $\geq 5 \mathrm{~mm} \mathrm{Hg}$ in pediatric (C) and adult (D) cohorts. Each dot represents the average value for 1 patient monitored from 11 PM to 7 AM. Boxes with dashed lines refer to a range of upper normal thresholds. Significant differences were determined by ANOVA with Bonferroni-corrected post hoc testing.

ship between intracranial volume change and pressure change $(\mathrm{dV} / \mathrm{dP})$. This relationship is assessed as changes in ICP following addition or removal of various volumes, and expressed in the pressure volume curve. ${ }^{32,33}$ During each cardiac contraction, the intracranial volume changes slightly and is accompanied by a change in pressure over the cardiac cycle. While the net intracranial volume $(\mathrm{dV})$ change during each cardiac contraction is about 1 $\mathrm{ml}, 4,47$ the amplitude of the single ICP wave is less than 4 $\mathrm{mm} \mathrm{Hg}$. Thus, we have previously shown that the MWA, which refers to the amplitude (dP) of the single pressure waves, is inversely associated with the intracranial compliance measured by the Spiegelberg compliance monitor. ${ }^{20}$ Impaired intracranial compliance and elevated ICP wave amplitudes can also be associated with reduced function of intracranial absorber mechanisms. ${ }^{36}$

Prior to shunting of hydrocephalus, the ICP wave amplitudes in patients are elevated, indicative of impaired intracranial compliance. ${ }^{22}$ Moreover, shunting normalizes the ICP waves, and adjustment of opening pressure can tailor levels of ICP waves. ${ }^{21}$ The literature is, however, scarce as to how shunt failure alters the ICP waves. ${ }^{23,40}$

The validity of ICP measurements in this study is limited by the descriptive and retrospective study design. The ICP scores were part of the basis for the diagnosis and will therefore influence the interpretation of the significance of the measurements in this cohort. However, the validity is to some extent supported by the diagnostic contribution of other factors such as the effect of valve adjustment, perioperative findings, and immediate postoperative clinical improvement, as well as the lack of readmission for shunt revision the following 30 days. In addition, the elevated ICP wave amplitudes were comparable with the abnormal levels previously reported in other studies. ${ }^{16,22}$ However, in this retrospective study, we have primarily described our results of monitoring ICP in patients with tentative shunt failure. A randomized study design is required to determine how ICP scores predict type of shunt failure.

\section{ICP Waves and ICP as Related to Age}

There are limited data in the literature as to how ICP dynamics relate to age and differ between pediatric and adult patients. One study reporting 46 patients between 17 and 86 years of age found a significantly positive association between age and resistance to CSF outflow, age and amplitude of ICP waves, and between age and slope of amplitude-pressure regression. ${ }^{11}$ Compared to the previous report, ${ }^{11}$ we found no correlation between age and mean ICP ( $0-80$ years), and no significant association be- 

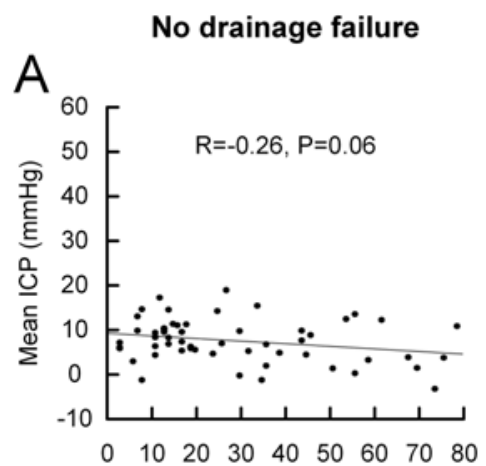

D

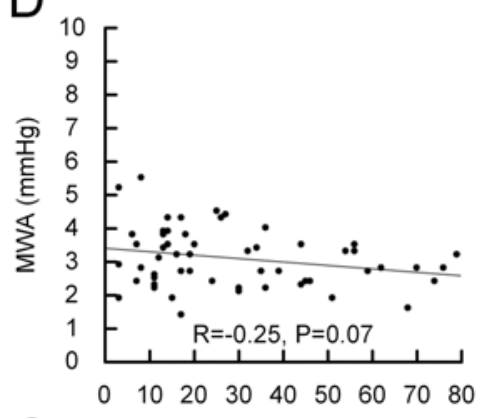

G

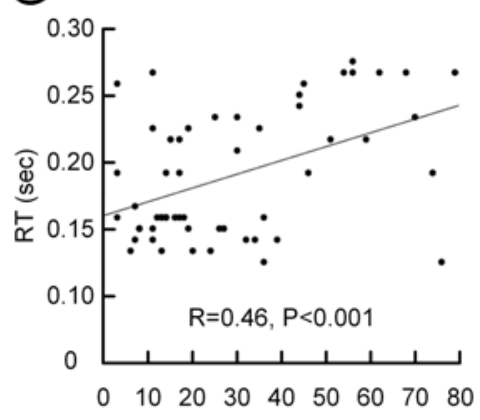

$\mathrm{J}$

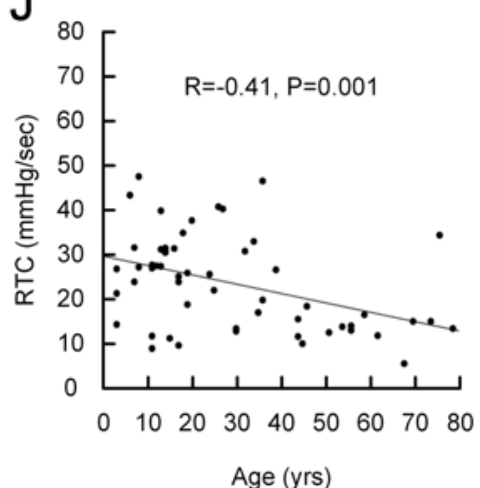

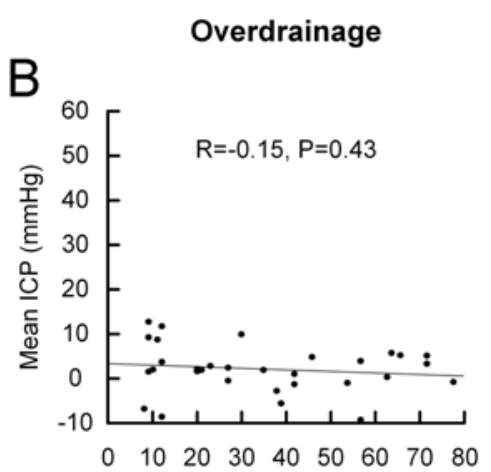

E

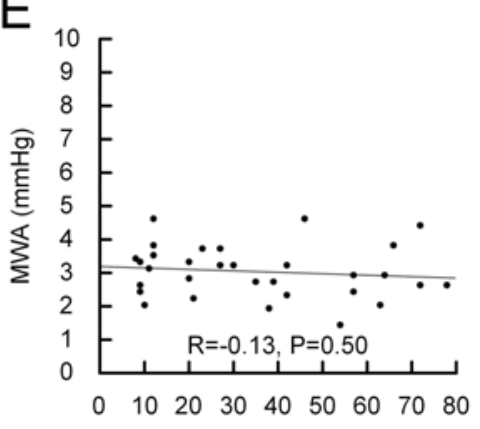

$\mathrm{H}$

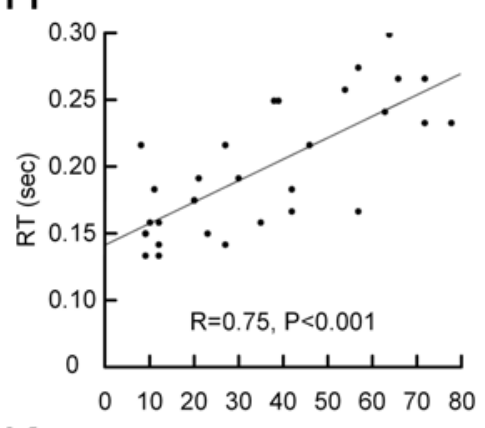

$\mathrm{K}$

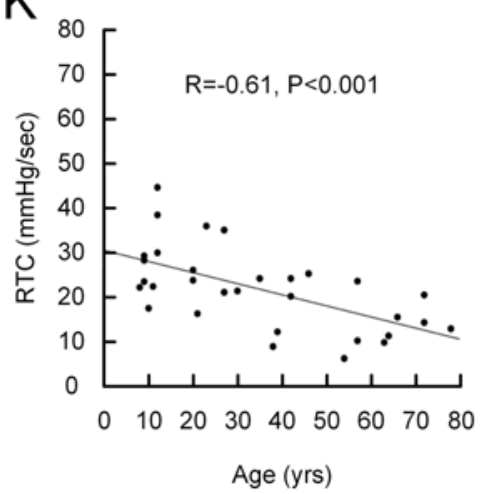

Underdrainage

C

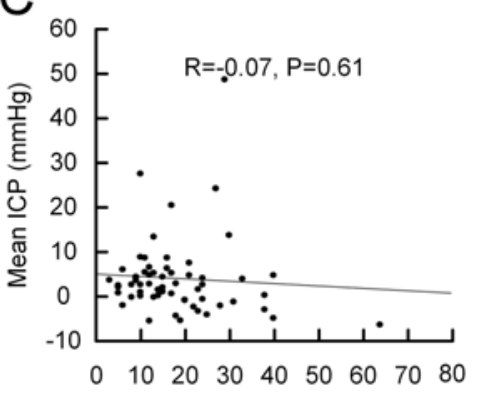

$\mathrm{F}$

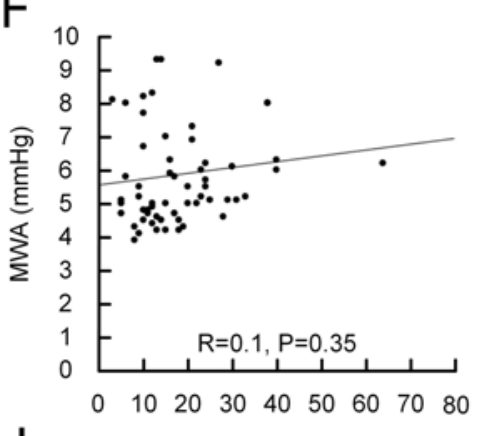

I

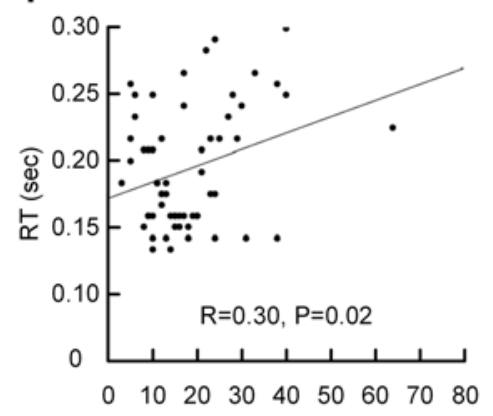

$\mathrm{L}$

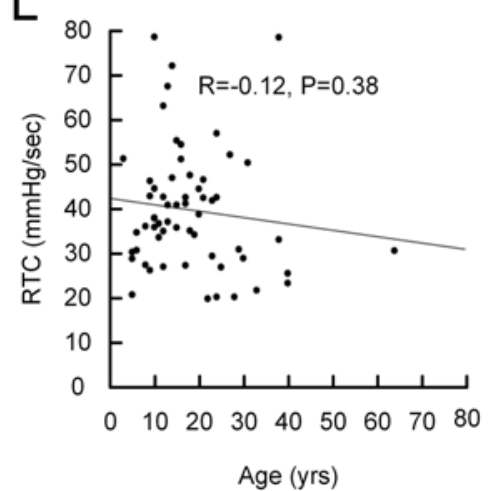

FIG. 5. Scatterplots showing the association between age and mean ICP (A-C), MWA (D-F), RT (G-I), and RTC (J-L) for patients in the no drainage failure, overdrainage, and underdrainage management groups. For each scatterplot the Pearson correlation coefficient with significance levels is shown.

tween age and MWA over the decades of life. On the other hand, a highly significant positive correlation between RT and age was found, which was accompanied by a negative association between age and RTC. This latter finding is related to the fact that RTC is determined by the relationship between amplitude and RT of the individual single pressure waves; accordingly, the RTC appears to be agedependent.

\section{Conclusions}

In this cohort of pediatric and adult patients with hydrocephalus and tentative shunt failure, the risk of ICP moni- 
toring was very low, and helped us avoid shunt revision in $49 \%$ of the patients with tentative shunt failure. Mean ICP best differentiated overdrainage, which was characterized by a higher percentage of episodes with negative mean ICP less than -5 to $-10 \mathrm{~mm} \mathrm{Hg}$. Underdrainage was best characterized by elevated MWA values, indicative of impaired intracranial compliance.

\section{References}

1. Abbott R, Epstein FJ, Wisoff JH: Chronic headache associated with a functioning shunt: usefulness of pressure monitoring. Neurosurgery 28:72-77, 1991

2. Al-Tamimi YZ, Sinha P, Chumas PD, Crimmins D, Drake J, Kestle J, et al: Ventriculoperitoneal shunt 30-day failure rate: a retrospective international cohort study. Neurosurgery 74:29-34, 2014

3. Albright AL: Hydrocephalus shunt practice of experienced pediatric neurosurgeons. Childs Nerv Syst 26:925-929, 2010

4. Alperin NJ, Lee SH, Loth F, Raksin PB, Lichtor T: MRintracranial pressure (ICP): a method to measure intracranial elastance and pressure noninvasively by means of MR imaging: baboon and human study. Radiology 217:877-885, 2000

5. Andresen M, Juhler M, Munch TN: Quality and safety of home ICP monitoring compared with in-hospital monitoring. Acta Neurochir Suppl 113:187-191, 2012

6. Bekar A, Doğan S, Abaş F, Caner B, Korfali G, Kocaeli H, et al: Risk factors and complications of intracranial pressure monitoring with a fiberoptic device. J Clin Neurosci 16:236-240, 2009

7. Bergsneider M, Yang I, Hu X, McArthur DL, Cook SW, Boscardin WJ: Relationship between valve opening pressure, body position, and intracranial pressure in normal pressure hydrocephalus: paradigm for selection of programmable valve pressure setting. Neurosurgery 55:851-859, 2004

8. Borgbjerg BM, Gjerris F, Albeck MJ, Hauerberg J, Børgesen SE: Frequency and causes of shunt revisions in different cerebrospinal fluid shunt types. Acta Neurochir (Wien) 136:189-194, 1995

9. Browd SR, Gottfried ON, Ragel BT, Kestle JR: Failure of cerebrospinal fluid shunts: part II: overdrainage, loculation, and abdominal complications. Pediatr Neurol 34:171-176, 2006

10. Browd SR, Ragel BT, Gottfried ON, Kestle JR: Failure of cerebrospinal fluid shunts: part I: obstruction and mechanical failure. Pediatr Neurol 34:83-92, 2006

11. Czosnyka M, Czosnyka ZH, Whitfield PC, Donovan T, Pickard JD: Age dependence of cerebrospinal pressure-volume compensation in patients with hydrocephalus. J Neurosurg 94:482-486, 2001

12. Drake JM, Kestle JR, Milner R, Cinalli G, Boop F, Piatt J Jr, et al: Randomized trial of cerebrospinal fluid shunt valve design in pediatric hydrocephalus. Neurosurgery 43:294-305, 1998

13. Drake JM, Kestle JR, Tuli S: CSF shunts 50 years on-past, present and future. Childs Nerv Syst 16:800-804, 2000

14. Eide PK: A new method for processing of continuous intracranial pressure signals. Med Eng Phys 28:579-587, 2006

15. Eide PK: Quantitative analysis of continuous intracranial pressure recordings in symptomatic patients with extracranial shunts. J Neurol Neurosurg Psychiatry 74:231-237, 2003

16. Eide PK, Bentsen G, Sorteberg AG, Marthinsen PB, Stubhaug A, Sorteberg W: A randomized and blinded singlecenter trial comparing the effect of intracranial pressure and intracranial pressure wave amplitude-guided intensive care management on early clinical state and 12-month outcome in patients with aneurysmal subarachnoid hemorrhage. Neurosurgery 69:1105-1115, 2011
17. Eide PK, Egge A, Due-Tønnessen BJ, Helseth E: Is intracranial pressure waveform analysis useful in the management of pediatric neurosurgical patients? Pediatr Neurosurg 43:472-481, 2007

18. Eide PK, Holm S, Sorteberg W: Simultaneous monitoring of static and dynamic intracranial pressure parameters from two separate sensors in patients with cerebral bleeds: comparison of findings. Biomed Eng Online 11:66, 2012

19. Eide PK, Sorteberg A, Meling TR, Sorteberg W: Baseline pressure errors (BPEs) extensively influence intracranial pressure scores: results of a prospective observational study. Biomed Eng Online 13:7, 2014

20. Eide PK, Sorteberg W: Association among intracranial compliance, intracranial pulse pressure amplitude and intracranial pressure in patients with intracranial bleeds. Neurol Res 29:798-802, 2007

21. Eide PK, Sorteberg W: Changes in intracranial pulse pressure amplitudes after shunt implantation and adjustment of shunt valve opening pressure in normal pressure hydrocephalus. Acta Neurochir (Wien) 150:1141-1147, 2008

22. Eide PK, Sorteberg W: Diagnostic intracranial pressure monitoring and surgical management in idiopathic normal pressure hydrocephalus: a 6-year review of 214 patients. Neurosurgery 66:80-91, 2010

23. Eide PK, Sroka M, Wozniak A, Sæhle T: Morphological characterization of cardiac induced intracranial pressure (ICP) waves in patients with overdrainage of cerebrospinal fluid and negative ICP. Med Eng Phys 34:1066-1070, 2012

24. Foltz EL, Blanks JP: Symptomatic low intracranial pressure in shunted hydrocephalus. J Neurosurg 68:401-408, 1988

25. Fouyas IP, Casey AT, Thompson D, Harkness WF, Hayward RD: Use of intracranial pressure monitoring in the management of childhood hydrocephalus and shunt-related problems. Neurosurgery 38:726-732, 1996

26. Fukuhara T, Luciano MG, Brant CL, Klauscie J: Effects of ventriculoperitoneal shunt removal on cerebral oxygenation and brain compliance in chronic obstructive hydrocephalus. J Neurosurg 94:573-581, 2001

27. Gelabert-González M, Ginesta-Galan V, Sernamito-García R, Allut AG, Bandin-Diéguez J, Rumbo RM: The Camino intracranial pressure device in clinical practice. Assessment in a 1000 cases. Acta Neurochir (Wien) 148:435-441, 2006

28. González-Darder JM, Barcia-Salorio JL: Pulse amplitude and volume-pressure relationships in experimental hydrocephalus. Acta Neurochir (Wien) 97:166-170, 1989

29. Greitz D: Radiological assessment of hydrocephalus: new theories and implications for therapy. Neurosurg Rev 27:145-167, 2004

30. Hommelstad J, Mads $\varnothing$ A, Eide PK: Significant reduction of shunt infection rate in children below 1 year of age after implementation of a perioperative protocol. Acta Neurochir (Wien) 155:523-531, 2013

31. Koskinen LO, Grayson D, Olivecrona M: The complications and the position of the Codman MicroSensor ${ }^{\mathrm{TM}}$ ICP device: an analysis of 549 patients and 650 sensors. Acta Neurochir (Wien) 155:2141-2148, 2013

32. Löfgren J, von Essen C, Zwetnow NN: The pressure-volume curve of the cerebrospinal fluid space in dogs. Acta Neurol Scand 49:557-574, 1973

33. Marmarou A, Shulman K, LaMorgese J: Compartmental analysis of compliance and outflow resistance of the cerebrospinal fluid system. J Neurosurg 43:523-534, 1975

34. Misaki K, Uchiyama N, Hayashi Y, Hamada J: Intracerebral hemorrhage secondary to ventriculoperitoneal shunt insertion-four case reports. Neurol Med Chir (Tokyo) 50:7679,2010

35. Muehlmann M, Koerte IK, Laubender RP, Steffinger D, Lehner M, Peraud A, et al: Magnetic resonance-based estimation of intracranial pressure correlates with ventriculo- 
peritoneal shunt valve opening pressure setting in children with hydrocephalus. Invest Radiol 48:543-547, 2013

36. Park EH, Eide PK, Zurakowski D, Madsen JR: Impaired pulsation absorber mechanism in idiopathic normal pressure hydrocephalus. Laboratory investigation. J Neurosurg 117:1189-1196, 2012

37. Pudenz RH, Foltz EL: Hydrocephalus: overdrainage by ventricular shunts. A review and recommendations. Surg Neurol 35:200-212, 1991

38. Rekate HL, Kranz D: Headaches in patients with shunts. Semin Pediatr Neurol 16:27-30, 2009

39. Sæhle T, Farahmand D, Eide PK, Tisell M, Wikkelsö C: A randomized controlled dual-center trial on shunt complications in idiopathic normal-pressure hydrocephalus treated with gradually reduced or "fixed" pressure valve settings. J Neurosurg 121:1257-1263, 2014

40. Schuhmann MU, Sood S, McAllister JP, Jaeger M, Ham SD, Czosnyka Z, et al: Value of overnight monitoring of intracranial pressure in hydrocephalic children. Pediatr Neurosurg 44:269-279, 2008

41. Simon TD, Whitlock KB, Riva-Cambrin J, Kestle JR, Rosenfeld M, Dean JM, et al: Revision surgeries are associated with significant increased risk of subsequent cerebrospinal fluid shunt infection. Pediatr Infect Dis J 31:551-556, 2012

42. Stagno V, Navarrete EA, Mirone G, Esposito F: Management of hydrocephalus around the world. World Neurosurg 79 (2 Suppl):S23.e17-S23.e20, 2013

43. Stehlin E, Malpas S, Heppner P, Hu P, Lim M, Budgett D: Implantable ICP monitor for improved hydrocephalus management. Acta Neurochir Suppl 114:101-104, 2012

44. Steinbok P, Milner R, Agrawal D, Farace E, Leung GK, Ng
I, et al: A multicenter multinational registry for assessing ventriculoperitoneal shunt infections for hydrocephalus. Neurosurgery 67:1303-1310, 2010

45. Stone JJ, Walker CT, Jacobson M, Phillips V, Silberstein HJ: Revision rate of pediatric ventriculoperitoneal shunts after 15 years. J Neurosurg Pediatr 11:15-19, 2013

46. Toma AK, Tarnaris A, Kitchen ND, Watkins LD: Investigating shunt function using continuous intracranial pressure monitoring in adults: single center experience. J Neurosurg 113:1326-1330, 2010

47. Wåhlin A, Ambarki K, Birgander R, Alperin N, Malm J, Eklund A: Assessment of craniospinal pressure-volume indices. AJNR Am J Neuroradiol 31:1645-1650, 2010

48. Zemack G, Romner B: Seven years of clinical experience with the programmable Codman Hakim valve: a retrospective study of 583 patients. J Neurosurg 92:941-948, 2000

\section{Author Contributions}

Conception and design: both authors. Acquisition of data: both authors. Analysis and interpretation of data: both authors. Drafting the article: both authors. Critically revising the article: both authors. Reviewed submitted version of manuscript: both authors. Approved the final version of the manuscript on behalf of both authors: Eide. Statistical analysis: both authors. Administrative/ technical/material support: both authors. Study supervision: Eide.

\section{Correspondence}

Per Kristian Eide, Department of Neurosurgery, Oslo University Hospital-Rikshospitalet, PB 4950 Nydalen, 0424 Oslo, Norway. email: per.kristian.eide@ous-hf.no. 